This item was submitted to Loughborough's Research Repository by the author.

Items in Figshare are protected by copyright, with all rights reserved, unless otherwise indicated.

\title{
What influences Chinese fashion retail? Shopping motivations, demographics and spending
}

\section{PLEASE CITE THE PUBLISHED VERSION}

https://doi.org/10.1108/JFMM-09-2017-0093

\section{PUBLISHER}

(C) Emerald Publishing Limited

\section{VERSION}

AM (Accepted Manuscript)

\section{PUBLISHER STATEMENT}

This work is made available according to the conditions of the Creative Commons Attribution-NonCommercial 4.0 International (CC BY-NC 4.0) licence. Full details of this licence are available at: http://creativecommons.org/licenses/by-nc/4.0/

\section{LICENCE}

CC BY-NC 4.0

\section{REPOSITORY RECORD}

Parker, Christopher J., and Lu Wenyu. 2019. "What Influences Chinese Fashion Retail? Shopping Motivations, Demographics and Spending”. Loughborough University. https://hdl.handle.net/2134/36823. 


\section{What Influences Chinese Fashion Retail? Shopping Motivations, Demographics and Spending}

Keywords: Motivation, Retailing, China, Gender, International Marketing, Consumer Behaviour

\section{Introduction}

Current marketing and design practice assume Chinese consumers shopping motivations match those of Western countries. Western fashion retailers are increasingly looking to capitalise upon China's expanding market, predicted to be worth over $\$ 320$ billion by 2020 (Lam and Chan, 2016). The importance of retail's expansion within China cannot be understated, with the United Nations (2016) stating that for continued economic growth and stability, the fashion industry depends upon successful growth in China. Given China's increasing prominence, it is surprising that China's distinctive shopping motivations have yet to be profiled. This is despite the disparity between Chinese and Wester behavioural motivations being well established (Arvidsson and Niessen, 2015; Rahman et al., 2018; Tsai and Men, 2017). Thus, the unique shopping motivations of Chinese fashion consumers are uncapitalised on.

The limited understanding of Chinese consumer preference and behaviour represents another critical limitation in designing effective marketing strategies in China. Specifically, the profiles of motivation relative to retail channel preference and purchase behaviours have yet to be given the critical insight they require (Bonetti et al., 2017). While traditional marketing practices have seen some success, multichannel marketing's expansion across diverse retail channels in dissimilar economic conditions makes China a more complex case than existing theory can support. The complexity is confounded by China's recent economic slowdown, making understanding consumer motivations more vital than ever (Bonetti et al., 2017). Since the experience of engaging in diverse retail channels alters the consumer's motivations and spending behaviours (Bonnin and Goudey, 2012; Ottar Olsen and Skallerud, 2011), retailers must base strategic decisions upon empirical consumer profiles instead of assumed parity to Western markets. Failure to understand such interconnections may lead to repeating the mistakes of earlier 
retailers who failed in the Chinese market (Hopkins, 2015). This study focuses on China due to its increasing prominence in international fashion retail and its representation of a developing nation. By understanding China's unique consumer profiles, this paper establishes theory in the form of consumer description whilst anticipating behaviours within other developing nations. Specifically, three research objectives are employed to investigate shopping motivations' influence on fashion retail engagement in China:

1. To understand how demographics associate with shopping motivations in China to inform more effective marketing strategies.

2. To understand how the retail channel preference (e-Commerce or high street) is influenced by shopping motivations in China to facilitate more effective retail channel design.

3. To understand how spending on fashion apparel is influenced by shopping motivations in China to identify salient motivators for efficient marketing strategy development.

This study restricts consumer shopping motivations to hedonic and unitarian dimensions. Hedonic and utilitarian shopping motivations provide a comprehensive depiction of variables that influence retail engagement (Childers et al., 2001; Parker and Wang, 2016). Multiple analysis of variance tests (MANOVA) are applied to investigate demographics' association with shopping motivations through. Direct logistic regression is applied to examine the influence of shopping motivation on retail channel preference and monthly expenditure. The statistical analysis offers an empirical understanding of Chinese consumer perceptions for fashion retailers seeking to develop their brand in China. In particular, this paper makes the following contributions:

- Demographics have limited association with shopping motivations in China, with Gender (women > men) and Age (18 - 35's > 35 - 55) only achieving small effect sizes. This is besides Occupation, Income and Education having no significant association at all.

- E-Commerce shopping preference is significantly influenced by Adventure, Social and Idea shopping motivations in a model that predicts $65 \%$ of all cases. 
- High monthly spending on fashion apparel is significantly influenced by Gratification and Idea motivations, and regular spending habits influenced by Value Motivations in a model that predicts $65 \%$ of all cases.

\section{Review Of Literature}

\section{Consumer Behaviour And Shopping Motivations}

Crane (2000) defines fashion as the apparel choices people make relative to their desired social identity and the tasks the apparel must fulfil. Thus, fashion relates to the consumer's self-concept in a way that few other products can match (Chebat et al., 2006; Parker and Doyle, 2018). Therefore, any attempt to describe motivation must focus on function and experience through which a person's 'self' can be realised. The excellent work of Carpenter et al. (2005) and Childers et al. (2001) highlights how both function and experience are essential to motivate purchase behaviours. By definition, motivation is a concept difficult to describe due to its indirectly observable characteristics (Lapointe and Perreault, 2013). However, hedonic (multisensory, fantasy or emotional focus; Hirschman and Holbrook, 1982) and utilitarian (functional focus; Babin et al., 1994) dimensions are key motivators for fashion shopping; as described within Table 1.

Table 1. Description of Shopping Motivations

\section{[Insert Table 1]}

Hedonic and utilitarian shopping motivations have been used with great success in contemporary research to define behaviour in contexts such as consumer engagement (Jones et al., 2006; Ruzeviciute and Kamleitner, 2017), technology enhancement (Blázquez, 2014), experience marketing (Tynan and McKechnie, 2009), sustainability (Ozdamar Ertekin et al., 2015) and cultural influences (Giovannini et al., 2015; Kooti et al., 2016). In each of these contexts hedonic and utilitarian motivation are established as powerful discriminating variables. 


\section{The Influence Of Demographics In Fashion Retail}

Contemporary western research recommends differentiating consumers by shopping motivations and demographics to develop targeted marketing strategies (Kalia, 2017; Kotzé et al., 2012). Such categorisation in China would allow for an increased targeting of consumer groups identified as having high shopping motivations. However, the degree to which this relates to China, or how demographics associated with Chinese shopping motivations are undefined.

Gender has a long-standing association with Electronic Commerce (e-Commerce) behaviour. In the USA, male and female college students show significant differences in shopping orientations, information searches and purchase experiences (Seock and Bailey, 2008). Such differences have a neurological basis, with women associating with greater levels of engagement and trust (Riedl et al., 2010), as well as Hedonic shopping activities (Huang and Yang, 2010; Kalia, 2017; Kotzé et al., 2012). Earlier research by Chen (2007) and Shaouf et al. (2016) found that men prefer e-Commerce channels more than women, who show a greater preference for high street retail. However, these conclusions focus on western consumers and therefore the generalisability to the Chinese market is untested. Thus, this study proposes Hypothesis 1a:

- H1a: Women express statistically greater levels of shopping motivation than men in China by a medium effect size; partial eta ${ }^{2}$ of .3>.

Age is another important theme in earlier research, with Rocha et al. (2005) showing that UK consumers of different genders and ages have alternative needs and experiences for fashion apparel. Adolescents in Taiwan and India echo this by expressing greater e-Commerce shopping motivations than older consumers (Huang and Yang, 2010; Kalia, 2017). Previous research furthermore shows younger consumers to be more engaged in fashion shopping as an enjoyable activity than older consumers (Bridges and Florsheim, 2008; Parker and Wang, 2016). The differences in behaviour towards fashion consumption may be explained by younger consumers (under 34) having a greater desire for self-expression and realisation of self-image congruity ${ }^{1}$ (Chebat et al., 2006).

\footnotetext{
${ }^{1}$ The connection between people, their actual or desired personal traits and others.
} 
Additionally, consumers over 35 are more aware of effort and time needs than younger consumers (Sharma et al., 2012). Conversely, Generation Y consumers (under 35) are the greatest driver behind luxury fashion consumption (Jay, 2012). However, such empiracle research does not exist within Chinese contexts. This leaves the generalizability of age's influence to the international audience unanswered. It is therefore imperative to determine the degree to which age influences Chinese consumers' purchase motivation. Thus, this study proposes Hypothesis $1 \mathrm{~b}$ :

- H1b: Under 35s express greater levels of shopping motivation than over $35 \mathrm{~s}$ in China by a medium effect size; partial eta $a^{2}$ of .3>.

Finally, education, income and occupation are traditionally important discriminating factors in marketing. This is because of their association with the consumer's potential disposable income (Goworek and McGoldrick, 2015; McGoldrick, 2002). Despite such a position being accepted within marketing theory, the academic literature has long been divided on how salary (Al-Somali et al., 2009) education (Cheawkamolpat, 2018; Mahmood et al., 2004) and occupation (Joo Park et al., 2006; Kalia, 2016) moderate consumer behaviour and motivation. For example, Hernández et al. (2011) showed that socioeconomic variables including income did not influence e-Commerce perceptions and behaviours. In contrast, Pattanaik et al. (2017) revealed that social standing influences shopping behaviours. Given the limited research into demographics' association with Chinese shopping motivations, assumptions as to which demographic variables to use as discriminating factors cannot be made with authority. Thus, this study proposes Hypothesis $1 \mathrm{c}-1 \mathrm{~d}$ :

- H1c: University Educated consumers express statistically greater levels of shopping motivation than High School educated consumers in China by a medium effect size; partial eta ${ }^{2}$ of $.3>$.

- H1d: Consumers with an above average income ( $¥ 80 k>$ ) express statistically greater levels of shopping motivation than average below ( $<¥ 80 k)$ within China by a medium effect size; partial eta ${ }^{2}$ of .3>. 
- H1e: Full-time occupation associated with higher levels of shopping motivation than students or self-employed consumers within China by a medium effect size; partial eta ${ }^{2}$ of .3>.

\section{High Street And E-Commerce Retail Channel Preference}

While an individual may experience the same basic motivations in life (e.g. shopping for their family; or Role Shopping) the experience of engaging in different environments influences their motivations (Bonnin and Goudey, 2012; Ottar Olsen and Skallerud, 2011). This is because hedonic shopping motivations depend on the way retailers deliver their services. Furthermore, experiential consumers may be more concerned with the Hedonic enjoyment, fantasy and sensual experiences of shopping than the functional acquisition of products (To et al., 2007). This advances the concept of high street retail having a higher ability to capitalise on consumer motivations than e-Commerce retail. High street retails dominance in this factor stems from the sensual nature of the built environment not replicable in the digital domain (Warnaby, 2013; Warnaby and Parker, 2017). However, the degree to which Chinese consumers' shopping motivation influences high street or e-Commerce preference is unknown.

Retail channels are physical or virtual locations where customers make a purchase. This paper accepts a common nomenclature of physical retail channels as 'bricks and mortar' stores catering for the economy, high street, diffusion or luxury market sectors (Jackson and Shaw, 2009). While high street refers to a specific sector of fashion retail, this paper considers all physical retail environments as 'high street' because of their universal ability to be visited and experienced across the widest range of human senses. ECommerce channels represent physical retail brands using the internet to facilitate sales (Zeng and Xu, 2010). Mobile Commerce (m-Commerce) is itself a subset of e-Commerce, being the same facilitation of retail activities, but restricted to mobile devices such as smartphones and tablets. While the products in $\mathrm{m}$-Commerce apps may be identical to that available via a website, $\mathrm{m}$-Commerce focuses on smaller screens in mobile situations. This differing focus leads to alternative methods of information presentation and consumer engagement (Gunasekaran and Ngai, 2011). Designers in turn focus on the different situations of the customer engagement with the device, often anticipating different goals and motivations the customer will experience (Parker, 2018). Given the 
parallel development of apps within China because of western services being blocked by the Great Firewall of China ${ }^{2}$, design standards and consumer experiences differ from the West. Such differences mean that inter-relations between technology and the consumer established in the West cannot be assumed within China. Thus, this study proposes Hypothesis 2.

- H2: Shopping motivations influence consumer retail channel preference (high street or e-Commerce) in China, with a predictive capability of $60 \%>$.

\section{Motivation's Influence On Fashion Purchase Behaviour}

Individual spending on fashion apparel in China is shown to be higher than in western countries, with a $10 \%$ annual market growth (Phillips, 2016; Statista, 2017). This is despite fashion apparel from international brands in China being around 120\% their equal price in the USA (McCarthy et al., 2017). As market leaders including Amazon demonstrate, understanding the unique shopping motivations of consumers has a prodigious potential to inform marketing strategies that achieve dominance (Sender, 2017). Without understanding the unique shopping motivations of Chinese consumers and their influence on fashion spending, powerful marketing strategies cannot be developed for China.

Self-reported expenditure on fashion items is a variable excluded by many models that stop at purchase intention (e.g. Kang and Kim, 2013; Tsai, 2005). In earlier research, Scarpi (2005) suggested that hedonic-orientated consumers spend more on nonessential goods (e.g. fashion items) than utilitarian-orientated consumers. This relates to how consumers with an active interest in being well-dressed have higher purchase intentions, albeit dependent upon additional environmental impacts (Jin Gam, 2011). However, the connection between e-Commerce and consumer spending as influenced by shopping motivation in China remains untested (McCormick et al., 2017). Thus, this study proposes Hypothesis 3.

\footnotetext{
2 Officially the Golden Shield Project (金盾工程)
} 
- H3: Consumers who spend more than $¥ 1 \mathrm{k}$ per month on fashion items will express higher levels of shopping motivation than those who spend $<¥ 1 \mathrm{k}$ per month for Chinese consumers by a statistically significant amount.

\section{Methodology}

\section{Setting And Sample}

403 native Chinese respondents being sourced through purposive sampling, surpassing the minimum sample size of 388 respondents was calculated with $\mathrm{G}^{*}$ Power; $f^{2}(v)=$ $.04, \alpha=.05$, Power $(1-\beta)=.8$, Grps $=2$, Measures $=8$ (Faul et al., 2017).

This study targeted both men and women to investigate $\mathrm{H} 1 \mathrm{a}$ (gender). To investigate H1b (age), participants were sampled from Chinese consumers aged 18 to 65. In addressing $\mathrm{H} 1 \mathrm{c}$ (education), both university (Undergraduate and Postgraduate) and high school (Mainstream and Senior) educated persons were sampled. H1d (income) was satisfied through sampling respondents with annual incomes from $<¥ 30 \mathrm{k}$ to $¥ 300 \mathrm{k}>$; respective of the Chinese average income of $¥ 68 \mathrm{k}$ per annum (Statista, 2018). Finally, respondents were sampled from full-time, self-employed, unemployed and student occupations; addressing $\mathrm{H} 1 \mathrm{e}$ (occupation). The sampling frame also required respondents to have recent experience with $\mathrm{m}$-Commerce fashion purchases (satisfying $\mathrm{H} 2$; retail channel preference) and an active interest in fashion (satisfying $\mathrm{H} 3$; monthly expenditure). Table 2 details descriptives of the sample.

Table 2. Participant Frequencies by Independent Variables

\section{[Insert Table 2]}

\section{Data Collection}

This study sampled respondents through the Chinese marketing service SoJump (wjx.cn). SoJump's successful use in earlier consumer behaviour research testifies to the suitability of the platform (e.g. Chang et al., 2014; Lien et al., 2017; Tang et al., 2018). Pre-registered respondents on the SoJump platform were administered the survey instrument over a four-week period in February 2017. As this study's sample drew from a non-specific region within China, regional bias was reduced. The selection process also required a reasonable level of computer literacy of all respondents. 


\section{Development Of The Survey Instrument}

A questionnaire was created in English and then professionally translated into Mandarin. The questionnaire comprised 32 questions measuring the constructs of Hedonic and Utilitarian Shopping motivations, with two positive and two negative statements per dependant variable. Before participation, the survey instructed respondents to visualise and consider their regular shopping experiences (either high street or e-Commerce) to prep their thoughts relative to the shopping focus of the research. Examples of the statements presented to respondents are shown in Table 3. The resulting scale items exhibited a minimum Cronbach's alpha coefficient of .85 , exceeding the preferred threshold of .8 for inter-item reliability (Devallis, 2012).

Table 3. Example statements presents to respondents ( $1=$ strongly disagree, $5=$ strongly agree)

\section{[Insert Table 3]}

20 Chinese Students at the University of Manchester (aged 18 - 23) took part in a pilot scheme during January 2017. In this pilot, all respondents had experience in eCommerce and high street retail channels, thus satisfying the sample's experience requirements (Churchill, 1979). This confirmed that all questions are understood and relevant to measuring their intended item.

The data associated with this paper are available 3 from: http://dx.doi.org/10.17632/bzn593sv5d.1

\section{Data Analysis}

Multivariate analysis of variance (MANOVA) tests investigated the association between demographics and shopping motivations $(\mathrm{H} 1 \mathrm{a}-\mathrm{H} 1 \mathrm{e})$. MANOVA was selected since the $\mathrm{H} 1 \mathrm{a}$ to $\mathrm{H} 1 \mathrm{e}$ consider the variation in the sample attributes. Analysis utilised MANOVA as an alternative to multiple ANOVAs to reduce the probability of Type II errors resulting from multiple comparisons; an occurrence probability of $34 \%{ }^{4}$.

\footnotetext{
${ }^{3}$ CC BY-NC 3.0 License

${ }^{4}$ Error Probability $=1-(1-\propto)^{n} ;$ where $\mathrm{n}=$ number of comparisons)
} 
Direct logistic regression investigated the influence of Shopping Motivations on retail channel preference and monthly expenditure ( $\mathrm{H} 2$ and $\mathrm{H} 3)$. This was because of Hypotheses 2 and 3 considering the dependent variables' variation as influenced by the independent variables. Both models contained eight independent variables relating to the eight Shopping Motivations of this paper; see Table 1.

Monthly spending on fashion items was categorised into $<¥ 1,000$ and $¥ 1,000>$ to represent luxury fashion purchases. $¥ 1 \mathrm{k}$ represents $18 \%$ of an average urban Chinese employee's monthly salary (Statista, 2018). As a proportion of pre-tax monthly income, $18 \%$ of the average salary equates to $f 395$ for an average British employee (ONS, 2018); the same price as a pair of luxury shoes (Jimmy Choo, 2018).

\section{Preliminary Data Analysis}

Preliminary testing checked for normality, linearity, univariate and multivariate outliers, homogeneity of variance-covariance matrices, and multicollinearity. Data was cleaned to ensure a minimum sample size of 20 respondents per cell to achieve suitable robustness within the tests (Tabachnick and Fidell, 2001, p. 251). Cases with a critical Mahalanobis distance less than 26.13 were included within the study to ensure multivariate normality (Pearson and Hartley, 1958). No serious violations of assumptions were encountered.

Retail Channel Preference's (H2) association with Monthly Spending on Fashion Items (H3) was investigated through a Chi-square test for independence (with Yates Continuity Correction). However, no significant association was observed, $\chi^{2}(1, n=403)=$ $.044, p=.833$, $p h i=.015$. Therefore, each hypothesis can be considered separately from the other's potential covariance or influence.

\section{Findings}

\section{Hedonic And Utilitarian Shopping Motivations}

The sample expressed high levels of motivation to shop for fashion items. Pairedsamples t-tests were applied to all components of shopping motivation to investigate inter-relational differences. All hedonic and utilitarian motivations exhibited statistically significant inter-item differences $(p<.000)$, with an average eta squared $\left(\eta^{2}\right)$ of.5; 
which shows a medium to large effect sizes. The sample showed high medians for shopping motivation across all elements of the survey; see Figure 1. All areas of hedonic and utilitarian motivation are shown to be important respondent shopping engagements. However greater salience can be attributed to the utilitarian motivations.

\section{[Insert Figure 1]}

Figure 1. A Box Plot $(95 \% \mathrm{Cl})$ showing hedonic and utilitarian Shopping Motivations, with $5=$ =very low engagement and $20=$ very high engagement

\section{Demographics (H1a To H1e)}

A series of one-way between-groups MANOVAs investigated shopping motivation's association with gender, age, education, income and occupation. As shown in Table 4, only Gender (Male and Female) and Age ( 35 and $36>$ ) achieved statistical significance between the groups. No statistically significant association between shopping motivations and Occupation, Income or Education was observed.

Hypothesis $\mathrm{H} 1 \mathrm{c}, \mathrm{H} 1 \mathrm{~d}$ and $\mathrm{H} 1 \mathrm{e}$ are therefore rejected.

Table 4. MANOVA: Association of Demographic Independent Variables with Shopping Motivations

\section{[Insert Table 4]}

A one-way between-groups MANOVA investigated the interaction effect between Gender and Age on Shopping Motivations. However, no statistically significant interaction between the two variables on the joint dependent variables of shopping motivation was observed, $F(8,382)=1.65, p=.110$; Wilks $\lambda=.967$; with a small effect size: $\eta p^{2}=.03$.

\section{Gender ( $H 1 a)$}

When the results of the dependent variables were considered separately relative to Gender, only three independent variables of hedonic shopping motivation achieved statistically significant differences when using a Bonferroni adjustment ( $\alpha=.006)$. Ranked by importance, these are:

1. Hedonic - Adventure: $F(1,401)=20.29, p<.000$, female reported a higher mean level of Adventure shopping motivation $(M=3.87, S D=.06)$ than men $(M=3.46, S D=.06)$, with a small effect size: $\eta p^{2}=.05$. 
2. Hedonic - Gratification: $F(1,401)=12.00, p=.001$, with women reporting a higher mean level of Gratification shopping motivation $(M=3.63, S D=.07)$ than men $(M=3.24, S D=.08)$, with a small effect size: $\eta p^{2}=.03$.

3. Hedonic - Role: $F(1,401)=11.25, p=.001$, with women reporting a higher mean level of Role shopping motivation $(M=4.02, S D=.06)$ than men $(M=3.75, S D=.06)$, with a small effect size: $\eta p^{2}=.03$.

Hypothesis $\mathrm{H} 1 \mathrm{a}$ is therefore accepted.

Age (H1b)

When the results of the dependent variables were considered separately in relation to Age, and using a Bonferroni adjustment $(\alpha=.006)$, only Utilitarian Shopping Motivation achieved a statistically significant difference; $F(1,391)=9.06, p=.003$. In the data, under 35s reported a higher mean level of Achievement Shopping motivation $(M=4.17, S D=.05)$ than over $35 \mathrm{~s}(M=3.90, S D=.07)$, with a small effect size: $\eta p^{2}=.02$.

Hypothesis $\mathrm{H} 1 \mathrm{~b}$ is therefore accepted.

\section{Retail Channel Preference (H2)}

Direct logistic regression assessed shopping motivations's impact on the preference for shopping through e-Commerce channels. The full model containing all predictors was statistically significant; $\chi^{2}(8, N=403)=38.13, p<.000$, showing that the model could distinguish between respondents who reported a preference for e-Commerce shopping over high street shopping. The model explained between 9.0\% (Cox and Snell $\mathrm{R}$ square) and $12.1 \%$ (Nagelkerke $\mathrm{R}$ squared) of the variance in e-Commerce shopping habits; classifying $64.8 \%$ of cases.

Hypothesis $\mathrm{H} 2$ is therefore accepted.

As shown in Table 5, only three of the independent variables made a unique statistically significant contribution to model (Adventure, Social and Idea shopping). The strongest predictor for e-Commerce shopping preference was idea shopping with an odds ratio of 1.39. This shows that the hedonic motivation of idea shopping influences respondents who preferred e-Commerce shopping were more than those who preferred high street 
shopping. The odds ratio of .58 for Adventure shopping was $<1$, showing that for every point increase in Adventure shopping respondents were .58 times less likely to shop online; controlling for other factors in the model.

Table 5. Direct logistic regression predicting the likelihood of e-Commerce shopping preference

\section{[Insert Table 5]}

\section{Fashion Apparel Spending (H3)}

Direct logistic regression investigated shopping motivation's impact on the likelihood that respondents would spend $¥ 1 \mathrm{k}>$ per month. The full model containing all predictors was statistically significant; $\chi^{2}(8, N=403)=38.94, p<.000$, showing that the model could distinguish between respondents who reported a preference for e-Commerce shopping over high street shopping. The model explained between 9.2\% (Cox and Snell $\mathrm{R}$ square) and $12.3 \%$ (Nagelkerke $\mathrm{R}$ squared) of the variance in e-Commerce preference, classifying $64.5 \%$ of cases.

Hypothesis H3 is therefore accepted.

As shown in Table 6, only three of the independent variables made a unique statistically significant contribution to model; Adventure Shopping, Social Shopping and Idea Shopping. The strongest predictor for e-Commerce shopping preference was Gratification Shopping with an odds ratio of 1.50 . This shows that the hedonic motivation of gratification shopping influences respondents who spend $¥ 1 \mathrm{k}>$ per month on fashion items were more than those who spent $<¥ 1 \mathrm{k}$ per month. The odds ratio of .77 for Value Shopping was $<1$, showing that for every point increase in Value shopping respondents were .77 times less likely to spend $¥ 1 \mathrm{k}>$ per month on fashion items, controlling for other factors in the model.

Table 6. Direct Logistic regression predicting monthly fashion spending

\section{[Insert Table 6]}




\section{Discussion}

\section{Demographics}

In marketing, demographics and shopping motivations are commonly utilised to develop consumer groups. Yet, before this paper, scant knowledge exists as to the how different demographics associate with shopping motivations within Chinese Fashion retail.

This study confirms Gender as an influential variable, with women associating with Adventure, Gratification and Role shopping motivations to a higher degree than men. Thus Hypothesis 1a is accepted, agreeing with earlier research (Arnold and Reynolds, 2003; Huang and Yang, 2010; Kalia, 2017; Seock and Bailey, 2008). However, this contradicts earlier research where we would expect women to express higher levels of motivation across all hedonic and utilitarian dimensions (Kotzé et al., 2012). This unexpected disagreement may stem from China's unique cultural identity to Western nations where the research was conducted. The gender difference shown in this paper also agrees with the previously shown lower shopping motivations of men (Gupta and Gentry, 2016). This outcome may stem from women being the main consumers in the commercial market in Western and Chinese cultures (Alesina et al., 2013). However, this study focused on post-experience reflection and therefore could not include factors that increase gendered differences. Consequently, women's understanding of goods, services and related retail channels are deeper than those of men (Bakewell and Mitchell, 2003).

This paper shows age associates with shopping motivations, with respondents under 35 associating with higher levels of Achievement Shopping. Thus, Hypothesis $1 \mathrm{~b}$ is accepted. This outcome agrees with Kooti et al. (2016) and Giovannini et al. (2015), who stated that lower age associates with higher purchase motivations. However, the results of this paper only accepts one shopping motivation associating with Age, rather than all motivations as previously positioned (Giovannini et al., 2015; Kooti et al., 2016; Rocha et al., 2005). Consequently, the age of Chinese consumers can no longer be seen as a universally segregating variable relating to shopping motivations. Regarding Rocha et al. (2005), this may be because $22 \%$ of their participants were much younger than in this study; aged 15-19. Achievement shopping's importance may be because of younger 
consumers being more engaged in shopping as an enjoyable activity (Bridges and Florsheim, 2008; Parker and Wang, 2016). The fact this paper's findings align with earlier research from Western (Bagdoniene and Zemblyte, 2009; Sorce et al., 2005) and Asian contexts (Teo, 2001; To et al., 2007; Xiao et al., 2016) suggests an industry preference to see younger consumers as highly motivated consumers.

Occupation, income and education level did not associate with variance in shopping motivations; rejecting Hypotheses $1 c-1 e$. This result contradicts the traditional marketing perspective that education, occupation and income influences purchase behaviour (Goworek and McGoldrick, 2015; Kalia, 2017). Furthermore, the lack of demographic association with shopping motivation is contrary to the 'Digital Divide' in China driven by gender, education and income levels (Wu et al., 2011). Acknowledging that consumers of low and high-income experience similar shopping motivations, a gulf exists between motivations to shop and the ability for consumers to make purchases. This paper hence settles the debate of education, occupation and income's association with shopping motivation within China. Despite these demographics being prominent social discriminators, marketers should not assume they will lead to differences in Chinese consumer retail engagement by motivation.

\section{Retail Channel Preference}

Delivering seductive retail experiences has long been an essential element of visual fashion marketing (Parker and Doyle, 2018). Yet, how shopping motivations influence retail channel preference in China has remained undefined, constraining the ability to capitalise upon each channel's strengths.

E-Commerce shopping preference in China is influenced by Adventure, Social and Idea shopping motivations in a model that predicts $65 \%$ of cases; accepting Hypothesis 2. Given the sensuality embodied within contemporary User Experience (UX) design, it is surprising that the motivations of Gratification, Value and Efficiency loaded on high street preference instead of e-Commerce channels. This contradicts earlier research that discounts available through e-Commerce environments offer better price value than available on the high street. Such influence can be explained through the multisensory nature of physical retail that cannot be replicated in a digital format 
(Bonnin and Goudey, 2012; Ottar Olsen and Skallerud, 2011). By this, the high street experience satisfies the visceral and emotional needs of the consumer, enabling their retail experiences to become entertainment. However, the influence of Adventure shopping on e-Commerce preference prohibits the conclusion that high street retail is the greatest proponent of satisfying consumer needs. Furthermore, the salience of Idea shopping motivations influencing e-Commerce preference agrees with earlier research underlining trend communication's importance to mobile retail channels (Yang and Kim, 2012).

\section{Monthly Fashion Spend}

Increasing consumer spending is the most essential element of fashion retail. Although earlier research suggests hedonic shopping motivations are influential in retail expenditure, this study could not replicate this finding. Therefore, the degree to which these variables are influential in China, and how shopping motivations influence behaviour must be questioned.

Monthly spending on fashion items of $¥ 1 \mathrm{k}$ or more is influenced by Gratification and Idea shopping. Conversely, monthly spending of less than $¥ 1 \mathrm{k}$ is influenced by Value shopping. Hypothesis 3 is therefore accepted. The influence of shopping motivations is of great importance to the wider research community because of its general exclusion from models stopping at purchase intention (Kang and Kim, 2013; Tsai, 2005). Although only Gratification and Idea shopping motivations influence high levels of spending, the results support hedonic shopping motivations influence on fashion purchases (Scarpi, 2005). The need to understand consumer spending influences has therefore been met (Davis, 2013; McCormick et al., 2017). However, these differentiating motivators are not the most prevalent of all motivations measured in the study. Therefore, the power of shopping motivations' influence must be tempered considering additional influencing factors. Focusing on Adventure, Gratification and Idea shopping motivations provides a suitable opportunity to capture the impetus of key consumers. However, this should not occur at the expense of utilitarian Efficiency, hedonic Achievement or the facilitation of Role shopping. 


\section{Conclusion}

In conclusion, this paper profiles the shopping motivations of Chinese consumers relative to demographics, fashion item expenditure and retail channel preference. Theory is established in the form of consumer description whilst anticipating behaviours within other developing nations. The understanding of Chinese fashion consumers' unique characteristics is enriched by providing empirical evidence of the key variable's influence.

A key finding of this paper is that shopping motivations have less impact on retail channel preference, monthly spending and associated with demographics than suggested by earlier research. Only hedonic motivations were shown to be influential, with utilitarian shopping motivations having no significant influence on the dependent variables. Utilitarian motivations therefore do not discriminate between retail channel choice and consumer behaviours. In revealing the motivational characteristics associated with retail channel preference, this paper provides a framework for marketers and designers to build upon in developing effective strategies. Thus, retail environments and e-Commerce channels can be designed to capitalise upon the unique characteristics of Chinese consumers. This is one of the earliest endeavours to empirically profile the influential characteristics of Chinese fashion consumers relative to shopping motivations, behaviour and preference.

Current research is underway to develop Virtual Reality shopping channels in China. As a retail channel that has yet to reach a consensus on how experiences should be delivered to consumers (Xue et al., 2018), virtual reality can benefit from the insights of this paper. Marketers and designers can also expect the same influences to apply to their emerging user base. As a result, this paper provides a basis for understanding the shopping motivations marketers and designers require to engage Chinese consumers across multiple fashion retail channels.

\section{Managerial Implications}

This study found Idea Shopping to have the highest influence on e-Commerce preference and is prominent in predicting consumer expenditure. Therefore, retailers must focus on creating innovative communicating trends methods through their 
Chinese apps and services. Marketing campaigns should promote such trend communication features within their retail apps. Furthermore, retailers should integrate post-purchase Achievement sharing via social media. This shall capitalise upon Chinese consumers under 35 years-old associating with higher levels of Achievement Shopping and placing greater importance on Social Shopping through e-Commerce channels. Integrating post-purchase sharing has the opportunity of capitalising on Electronic Word of Mouth (eWOM) a strong channel for innovation diffusion. Finally, the finding that Gratification shopping is the most prominent predictor of Chinese consumer expenditure, and Gratification's association with High Street retail preference means that physical retail remains the dominant channel for delivering experiential and seductive interactions. Retailers should focus on the shopping experience as a stressreducing experience alongside seasonal trend communication. Therefore, incorporating experiential store features such as luxury coffee bars into stores in China would capitalise upon pre-existing social motivations while being sympathetic to the idiosyncratic nature of luxury fashion branding.

\section{Limitations And Future Studies}

This paper is limited in its focus on physical (gender, age and shopping environment) and motivational influences rather than psychological or attitudinal attributes. Future studies may consider investigating psychological and attitudinal elements of Chinese fashion retail to offer a deeper understanding of why the parameters of this paper influence shopping motivations. The degree to which variables including shopping motivations translates to purchase behaviours requires more research in the fashion context to increase the strategic targeting of marketing campaigns. Future studies shall need a larger sample than this paper to distinguish small yet significant effect sizes without the risk of Type II errors. Finally, a qualitative investigation can open doors for a deeper understanding of psychological factors influencing motivation as reported in this paper.

\section{References}

Al-Somali, S.A., Gholami, R. and Clegg, B. (2009), “An investigation into the acceptance of online banking in Saudi Arabia", Technovation, Vol. 29 No. 2, pp. 130-141. 
Alesina, A., Giuliano, P. and Nunn, N. (2013), "On the Origins of Gender Roles: Women and the Plough", The Quarterly Journal of Economics, Vol. 128 No. 2, pp. 469-530.

Arnold, M.J. and Reynolds, K.E. (2003), "Hedonic shopping motivations", Journal of Retailing, Vol. 79 No. 2, pp. 77-95.

Arvidsson, A. and Niessen, B. (2015), "Creative mass. Consumption, creativity and innovation on Bangkok's fashion markets", Consumption Markets \& Culture, Vol. 18 No. 2, pp. 111-132.

Babin, B.J., Darden, W.R. and Griffin, M. (1994), "Work and/or Fun: Measuring Hedonic and Utilitarian Shopping Value", Journal of Consumer Research, Vol. 20 No. 4, pp. 644-656.

Bagdoniene, L. and Zemblyte, J. (2009), “Online Shopping Motivation Factors and Their Effect on Lithuanian Consumers", Economics and Management, Vol. 14 No. 1, pp. 367-375.

Bakewell, C. and Mitchell, V. (2003), "Generation Y female consumer decision-making styles", International Journal of Retail \& Distribution Management, Vol. 31 No. 2, pp. 95-106.

Blázquez, M. (2014), "Fashion shopping in multichannel retail: The role of technology in enhancing the customer experience", International Journal of Electronic Commerce, Vol. 18 No. 4, pp. 97-116.

Bonnin, G. and Goudey, A. (2012), "The kinetic quality of store design: An Exploration of its influence on shopping experience", Journal of Retailing and Consumer Services, Vol. 19 No. 6, pp. 637-643.

Bridges, E. and Florsheim, R. (2008), "Hedonic and utilitarian shopping goals: The online experience", Journal of Business Research, Vol. 61 No. 4, pp. 309-314.

Carpenter, J.M., Moore, M. and Fairhurst, A.E. (2005), "Consumer shopping value for retail brands", Journal of Fashion Marketing and Management, Emerald Group Publishing Limited, Vol. 9 No. 1, pp. 43-53.

Chang, Y., Dong, X. and Sun, W. (2014), "Influence of Characteristics of the Internet of 
Things on Consumer Purchase Intention", Social Behavior and Personality: An International Journal, Vol. 42 No. 2, pp. 321-330.

Cheawkamolpat, P. (2018), "Online shopping behavior: a study of consumers in bangkok", AU Journal of Management, Vol. 7 No. 2, pp. 1-11.

Chebat, J.-C., Sirgy, M.J. and St-James, V. (2006), “Upscale image transfer from malls to stores: A self-image congruence explanation", Journal of Business Research, Vol. 59 No. 12 , pp. $1288-1296$.

Chen, C. (2007), "The Impact of Commodity Types on Gender Differences in Online Shopping Preference", Shopping Mall Modernization, Vol. 2 No. 1, pp. 163-164.

Childers, T.L., Carr, C.L., Peck, J. and Carson, S. (2001), “Hedonic and utilitarian motivations for online retail shopping behavior", Journal of Retailing, Vol. 77 No. 4 , pp. 511-535.

Churchill, G.A. (1979), “A Paradigm for Developing Better Measures of Marketing Constructs", Journal of Marketing Research, Vol. 16 No. 1, p. 64.

Crane, D. (2000), Fashion and Its Social Agendas: Class, Gender, and Identity in Clothing, The University of Chicago Press, Chicago, USA.

Davis, L.Y. (2013), “Let us go shopping: exploring Northwest Chinese consumers' shopping experiences", International Journal of Consumer Studies, Vol. 37 No. 4, pp. 353-359.

Devallis, R.F. (2012), Scale Development: Theory and Application, 3rd ed., SAGE, Thousand Oaks, USA.

Faul, F., Erdfelder, E., Lang, A.-G. and Buchner, A. (2017), "G*Power", Heinrich-HeineUniversität, Düsseldorf, Germany, available at: http://www.gpower.hhu.de/en.html.

Giovannini, S., Xu, Y. and Thomas, J. (2015), "Luxury fashion consumption and Generation Y consumers", Journal of Fashion Marketing and Management, Emerald Group Publishing Limited, Vol. 19 No. 1, pp. 22-40.

Goworek, H. and McGoldrick, P. (2015), Retail Marketing Management: Principles and 
Practices, Pearson, Harlow, UK.

Gunasekaran, A. and Ngai, E.W.T. (2011), "The future of operations management: An outlook and analysis", International Journal of Production Economics, Elsevier, Vol. 135 No. 2, pp. 687-701.

Gupta, S. and Gentry, J.W. (2016), "Construction of gender roles in perceived scarce environments - Maintaining masculinity when shopping for fast fashion apparel", Journal of Consumer Behaviour, Vol. 15 No. 3, pp. 251-260.

Hernández, B., Jiménez, J., Martín, M.J. and José Martín, M. (2011), “Age, gender and income: do they really moderate online shopping behaviour?", Online Information Review, Emerald Group Publishing Limited, Vol. 35 No. 1, pp. 113-133.

Hirschman, E.C. and Holbrook, M.B. (1982), “Hedonic Consumption: Emerging Concepts, Methods and Propositions", Journal of Marketing, Vol. 46 No. 3, p. 92.

Huang, J.H. and Yang, Y.C. (2010), “Gender differences in adolescents' online shopping motivations", African Journal of Business Management, Vol. 4 No. 6, pp. 849-857.

Jackson, T. and Shaw, D. (2009), Mastering Fashion Marketing, Palgrave Macmillan, Basingstoke, UK.

Jay, E. (2012), "New breed of consumer shakes up luxury fashion", Mobile Marketer, available at: www.mobilemarketer.com/cms/opinion/columns/12361.html (accessed 12 December 2017).

Jimmy Choo. (2018), "AMELY 105", Jimmy Choo Online Store, available at: https://www.jimmychoo.com/en/women/shoes/amely-105/nude-printedmetallic-leather-slingback-wedges-AMELY105PZL120008.html?cgid=womenshoes\#psortd1=1\&psortb1=bestMatch\&srule=price-low-tohigh\&sz=40\&start=1\&productsearch=true (accessed 3 July 2018).

Jin Gam, H. (2011), “Are fashion-conscious consumers more likely to adopt eco-friendly clothing?", Journal of Fashion Marketing and Management, Emerald Group Publishing Limited, Vol. 15 No. 2, pp. 178-193.

Jones, M.A., Reynolds, K.E. and Arnold, M.J. (2006), "Hedonic and utilitarian shopping 
value: Investigating differential effects on retail outcomes", Journal of Business Research, Vol. 59 No. 9, pp. 974-981.

Joo Park, E., Young Kim, E. and Cardona Forney, J. (2006), “A structural model of fashionoriented impulse buying behavior", Journal of Fashion Marketing and Management, Emerald Group Publishing Limited, Vol. 10 No. 4, pp. 433-446.

Kalia, P. (2016), “Demographic Profile of Online Shoppers: An Overview”, Indian Journal of Economics and Development, Vol. 12 No. 1a, p. 37.

Kalia, P. (2017), “Does Demographics Affect Purchase Frequency in Online Retail?", International Journal of Online Marketing, Vol. 7 No. 2, pp. 42-56.

Kang, J. and Kim, S.-H. (2013), "What Are Consumers Afraid of? Understanding Perceived Risk toward the Consumption of Environmentally Sustainable Apparel", Family and Consumer Sciences Research Journal, Vol. 41 No. 3, pp. 267-283.

Kooti, F., Lerman, K., Aiello, L.M., Grbovic, M., Djuric, N. and Radosavljevic, V. (2016), "Portrait of an Online Shopper", Proceedings of the Ninth ACM International Conference on Web Search and Data Mining - WSDM '16, ACM Press, New York, New York, USA, pp. 205-214.

Kotzé, T., North, E., Stols, M. and Venter, L. (2012), “Gender differences in sources of shopping enjoyment", International Journal of Consumer Studies, Vol. 36 No. 4, pp. 416-424.

Lam, T. and Chan, T. (2016), China's Apparel Market, Hong Kong, available at: https://www.fbicgroup.com/sites/default/files/MarketOveriew_p1.pdf.

Lapointe, M.-C. and Perreault, S. (2013), “Motivation: understanding leisure engagement and disengagement", Loisir et Société / Society and Leisure, Vol. 36 No. 2, pp. 136-144.

Lien, C.-H., Cao, Y. and Zhou, X. (2017), "Service quality, satisfaction, stickiness, and usage intentions: An exploratory evaluation in the context of WeChat services", Computers in Human Behavior, Vol. 68, pp. 403-410.

Mahmood, M.A., Bagchi, K. and Ford, T.C. (2004), “On-line Shopping Behavior: Cross- 
Country Empirical Research", International Journal of Electronic Commerce, Vol. 9 No. 1, pp. 9-30.

McCarthy, K., Perkins, B., Pope, N., Portaluppi, L., Scaramuzzi, V. and Su, L. (2017), Global Powers of Luxury Goods 2017, Westlake, USA, available at: https://www2.deloitte.com/global/en/pages/consumer-business/articles/gx-cbglobal-powers-of-luxury-goods.html.

McCormick, H., Parker, C.J. and Magrath, V.C. (2017), “Emotional Response Beyond PAD: the Digital Retail Emotions Scale (DRES) for m-commerce apps", 3rd International Colloquium of Design, Branding and Marketing (ICDBM), Bournemouth, UK.

McGoldrick, P.J.. (2002), Retail Marketing, Second., McGraw-Hall Education, London.

ONS. (2018), "Average Weekly Earnings time series dataset (EMP)", Office for National Statistics, available at: https://www.ons.gov.uk/employmentandlabourmarket/peopleinwork/earningsa ndworkinghours/timeseries/kab9/emp (accessed 3 July 2018).

Ottar Olsen, S. and Skallerud, K. (2011), "Retail attributes' differential effects on utilitarian versus hedonic shopping value", Journal of Consumer Marketing, Vol. 28 No. 7, pp. 532-539.

Ozdamar Ertekin, Z., Atik, D., Ertekin, Z.O. and Atik, D. (2015), "Sustainable markets: Motivating factors, barriers, and remedies for mobilization of slow fashion", Journal of Macromarketing, Vol. 35 No. 1, pp. 53-69.

Parker, C. (2018), "Reimagining m-Commerce App Design: The Development of Seductive Marketing through UX", in Oflazoglu, S. (Ed.), Marketing, InTech, London, UK, pp. 39-56.

Parker, C.J. and Doyle, S.A. (2018), "Designing Indulgent Interaction: Luxury Fashion, MCommerce, and Übermensch", in Ozuem, W. and Azemi, Y. (Eds.), Digital Marketing Strategies for Fashion and Luxury Brands, IGI Global, Hershey, USA, pp. 1-21.

Parker, C.J. and Wang, H. (2016), "Examining hedonic and utilitarian motivations for mcommerce fashion retail app engagement", Journal of Fashion Marketing and 
Management, Vol. 20 No. 4, pp. 487-506.

Pattanaik, S., Mishra, B.B. and Moharana, T.R. (2017), "How Consumer Demographics is Associated with Shopping Behaviour? A Study on Indian Consumers", Siddhant- A Journal of Decision Making, Vol. 17 No. 2, p. 195.

Pearson, E.S. and Hartley, H.O. (Eds.). (1958), Biometrika Tables for Statisticians, Cambridge University Press, New York, USA.

Phillips, S. (2016), China's Middle Income Consumers, China-Britain Business Council, UK, available at: http://www.cbbc.org/cbbc/media/cbbc_media/KnowledgeLibrary/Reports/Sector Profile/CBBC-China-s-Middle-Income-Consumers.pdf (accessed 25 July 2017).

Rahman, O., Fung, B.C.M., Chen, Z., Chang, W.-L. and Gao, X. (2018), “A study of apparel consumer behaviour in China and Taiwan", International Journal of Fashion Design, Technology and Education, Vol. 11 No. 1, pp. 22-33.

Riedl, R., Hubert, M. and Kenning, P. (2010), "Are there neural gender differences in online trust? an fMRI study on the perceived trustworthiness of eBay offers", Mis Quarterly, Vol. 34 No. 2, pp. 397-428.

Rocha, M.A. V., Hammond, L. and Hawkins, D. (2005), “Age, gender and national factors in fashion consumption", Journal of Fashion Marketing and Management, Vol. 9 No. 4, pp. 380-390.

Ruzeviciute, R. and Kamleitner, B. (2017), "Attracting new customers to loyalty programs: The effectiveness of monetary versus nonmonetary loyalty programs", Journal of Consumer Behaviour, Vol. 16 No. 6, pp. e113-e124.

Scarpi, D. (2005), "Hedonic and Utilitarian Behaviour in Specialty Shops", The Marketing Review, Vol. 5 No. 1, pp. 31-44.

Sender, T. (2017), "How Amazon is disrupting the fashion sector - 29th June 2017", Mintel, London, UK, available at: http://academic.mintel.com/display/841477/ (accessed 24 July 2017).

Seock, Y.-K. and Bailey, L.R. (2008), "The influence of college students' shopping 
orientations and gender differences on online information searches and purchase behaviours", International Journal of Consumer Studies, Vol. 32 No. 2, pp. 113-121.

Shaouf, A., Lü, K. and Li, X. (2016), "The effect of web advertising visual design on online purchase intention: An examination across gender", Computers in Human Behavior, Vol. 60, pp. 622-634.

Sharma, P., Chen, I.S.N. and Luk, S.T.K. (2012), "Gender and age as moderators in the service evaluation process", Journal of Services Marketing, Vol. 26 No. 2, pp. 102114.

Sorce, P., Perotti, V. and Widrick, S. (2005), "Attitude and age differences in online buying", International Journal of Retail \& Distribution Management, Vol. 33 No. 2, pp. 122-132.

Statista. (2017), "Annual expenditure on clothing and footwear in the United Kingdom (UK) from 2005 to 2016", Office for National Statistics, available at: https://www.statista.com/statistics/300840/annual-expenditure-on-clothing-andfootwear-in-the-united-kingdom-uk/ (accessed 21 July 2017).

Statista. (2018), "Average annual salary of an employee in urban China from 2006 to 2016 (in yuan)", Statista, available at: https://www.statista.com/statistics/278349/average-annual-salary-of-anemployee-in-china/ (accessed 3 July 2018).

Tabachnick, B.G. and Fidell, L.S. (2001), Using Multivariate Statistics, edited by Pascal, R. and Brown, W., 4th ed., Allyn and Bacon, Needham Heights.

Tang, C., Xiong, Y., Wu, H. and Xu, J. (2018), "Adaptation and assessments of the Chinese version of the ICECAP-A measurement", Health and Quality of Life Outcomes, Vol. 16 No. 1, p. 45.

Teo, T.S.H. (2001), "Demographic and motivation variables associated with Internet usage activities", Internet Research, Vol. 11 No. 2, pp. 125-137.

To, P.-L., Liao, C. and Lin, T.-H. (2007), "Shopping motivations on Internet: A study based on utilitarian and hedonic value", Technovation, Vol. 27 No. 12, pp. 774-787. 
Tsai, S. (2005), "Utility, cultural symbolism and emotion: A comprehensive model of brand purchase value", International Journal of Research in Marketing, Vol. 22 No. 3, pp. 277-291.

Tsai, W.-H.S. and Men, L.R. (2017), “Consumer engagement with brands on social network sites: A cross-cultural comparison of China and the USA", Journal of Marketing Communications, Routledge, Vol. 23 No. 1, pp. 2-21.

Tynan, C. and McKechnie, S. (2009), "Experience marketing: A review and reassessment", Journal of Marketing Management, Vol. 25 No. 5/6, pp. 501-517.

United Nations. (2016), "World Economic Situation and Prospects”, UN/DESA, New York, USA, available at: http://www.un.org/en/development/desa/policy/wesp/wesp_current/2016wesp _ch1_en.pdf (accessed 24 July 2017).

Warnaby, G. (2013), "Synchronising retail and space: using urban squares for competitive place differentiation", Consumption Markets \& Culture, Routledge, Vol. 16 No. 1, pp. 25-44.

Warnaby, G. and Parker, C.J. (2017), "Walking Cities (or not): How walking impacts the city experience?", in Campelo, A. (Ed.), Mobility, Marketing, and the City: The Discovery of Experience, Edward Elgar Publishing, Cheltenham, UK, pp. 203-217.

Wu, L., Cai, Y. and Liu, D. (2011), “Online shopping among Chinese consumers: an exploratory investigation of demographics and value orientation", International Journal of Consumer Studies, Vol. 35 No. 4, pp. 458-469.

Xiao, L., Guo, Z., D’Ambra, J. and Fu, B. (2016), "Building loyalty in e-commerce", Program, Vol. 50 No. 4, pp. 431-461.

Xue, L., Parker, C.J. and McCormick, H. (2018), “A Virtual Reality and Retailing Literature Review: Current Focus, Underlying Themes and Future Directions", 4th International $A R$ \& VR Conference 2018: The Power of $A R$ \& VR for Business, Creative Augmented Virtual Reality Hub, Manchester, UK.

Yang, K. and Kim, H.-Y. (2012), "Mobile shopping motivation: an application of multiple 
Motivations for Fashion Shopping

discriminant analysis", International Journal of Retail \& Distribution Management, Vol. 40 No. 10 , pp. $778-789$.

Zeng, C. and Xu, D. (2010), "Views on the Development of E-Commerce of Chinese Clothing Industry", International Journal of Business and Management, Vol. 5 No. 8, pp. 215-218. 